\title{
Overexpression of the long non-coding RNA, linc- $U B C I$, is associated with poor prognosis and facilitates cell proliferation, migration, and invasion in colorectal cancer
}

\author{
This article was published in the following Dove Press journal: \\ OncoTargets and Therapy \\ 22 February 2017 \\ Number of times this article has been viewed
}

\section{Xunfeng Gao \\ Jianfan Wen \\ Peng Gao \\ Guowei Zhang \\ Gangqing Zhang}

Department of General Surgery, The Second People's Hospital of Guangdong Province, The Third Clinical Medical College of Southern Medical University, Guangzhou, Guangdong, People's Republic of China
Correspondence: Gangqing Zhang; Jianfan Wen

Department of General Surgery, The Second People's Hospital of Guangdong Province, The Third Clinical Medical College of Southern Medical University, 466 Xingang Middle Road, Guangzhou, Guangdong 510317, People's Republic of China

Email zhanggangqing@yahoo.com; wenjianfan927@I63.com

\begin{abstract}
Long non-coding RNAs (lncRNAs) serve comprehensive roles in various diseases, including cancer. IncRNA upregulated in bladder cancer 1 (linc-UBC1) is a notable biomarker of prognosis in certain cancer types; however, its involvement in the progression of colorectal cancer (CRC) remains unknown. The present study aimed to investigate the expression of lincUBC1 in patients with CRC and to investigate its effect on CRC cells. The expression levels of linc-UBC1 were estimated by reverse transcription-quantitative polymerase chain reaction in clinical CRC specimens and matched adjacent non-tumor mucosa from 96 cases of CRC, as well as in a number of CRC cell lines. In addition, the biological roles of linc-UBC1 were examined using a cell counting kit- 8 assay, flow cytometry, and migration and invasion assays following the downregulation of linc-UBC1 by small interfering RNA. The results revealed that linc-UBC1 was significantly overexpressed in CRC tissues and the majority of CRC cell lines compared with the matched non-tumor mucosa and normal intestinal epithelial cells. Furthermore, high expression levels of linc-UBC1 were significantly associated with large tumor size, greater tumor depth, lymph node metastasis, and advanced tumor-node-metastasis stages. Patients with abnormal expression of linc-UBC1 had poorer overall survival times according to Kaplan-Meier analyses. Furthermore, multivariate Cox regression analysis indicated that lincUBC1 was a significant independent prognostic factor. The results also revealed that reducing the expression of linc-UBC1 led to the inhibition of migration, invasion, and proliferation of $\mathrm{CRC}$ cells in vitro. Taken together, the results of the present study suggest that overexpression of linc-UBC1 promotes proliferation and metastasis in $\mathrm{CRC}$, and may be considered as a novel diagnostic marker of CRC.
\end{abstract}

Keywords: linc-UBC1, long non-coding RNA, colorectal cancer, diagnosis, prognosis, gene function

\section{Introduction}

Colorectal cancer $(\mathrm{CRC})$ is the third most prevalent type of cancer in males and the second most prevalent in females, with an estimated 693,900 mortalities occurring in 2012, worldwide. ${ }^{1}$ According to a recent report, the CRC incidence and mortality rates in China have been increasing in the past few years due to late tumor stages at the time of presentation and rapid progression. ${ }^{2}$ Occurrence and progression of cancer are multistep processes that involve epithelial cell proliferation, apoptosis, and differentiation. ${ }^{3,4}$ In recent years, substantial progress has been made in the diagnosis and treatment of $\mathrm{CRC}$; however, mortality caused by $\mathrm{CRC}$ remains high. Therefore, 
various studies have been conducted to investigate the molecular abnormalities associated with $\mathrm{CRC}$, in order to further elucidate its molecular pathogenesis..$^{5-7}$

Long non-coding RNAs (lncRNAs), which were first described by Brockdorff et al in 1992, are defined as nonprotein-coding RNA molecules having $>200$ nucleotides in length, which may be located in the cell nucleus or cytoplasm. ${ }^{8}$ In recent years, an increasing number of lncRNAs have been reported to play crucial roles in a wide variety of biological processes and to be involved in almost all aspects of gene regulation, including genomic imprinting, chromatin modification, and posttranscriptional processing. ${ }^{9-12}$ Furthermore, numerous studies have indicated that certain lncRNAs are critical for various cellular processes, such as apoptosis, cell cycle progression, and cell invasion and proliferation. It has been demonstrated that the dysregulation of IncRNAs, such as HOX transcript antisense RNA (HOTAIR), Dreh, lncRNAATB, LINC00473, and prostate cancer-associated transcript 5 , may have a negative effect on the prognosis of patients with breast cancer, hepatocellular carcinoma, non-small cell lung cancer, gastric cancer, and prostate cancer by promoting cell proliferation and invasion..$^{13-17}$ Likewise, the dysregulation of MYCLo-2, CCAT1, and CCAT3 8 may have a significant effect in CRC by regulating MYC, which is known to regulate lncRNAs and has been implicated in cancer cell proliferation and tumorigenesis. ${ }^{18,19}$ Therefore, these lncRNAs have been the focus of numerous studies worldwide.

The present study focused on the lncRNA upregulated in bladder cancer 1 (linc-UBC1), which has a transcript length of 2,616 bp and is located on chromosome 1q32.1. It has been confirmed that linc-UBC1 physically combines with polycomb repressive complex 2 (PRC2), of which the core components are SUZ12 and enhancer of zeste 2 (EZH2). Hence, linc-UBC1 may mediate cell growth, proliferation, and invasion and has been shown to be upregulated in bladder and gastric cancer. ${ }^{20,21}$ It is estimated that a substantial proportion (24\%) of lncRNAs expressed in a cell, including some that are strongly associated with CRC, are physically associated with PRC2. ${ }^{22,23}$ The dysregulation of linc-UBC1 has been recognized to be a potential biological signature of $\mathrm{CRC}$; however, its specific expression pattern with regard to CRC remains to be elucidated.

This study aimed to explore the gene expression pattern of linc-UBC1 in CRC cell lines and in tissue samples from CRC patients and to analyze the potential associations between clinicopathological features and linc-UBC1 levels. Furthermore, the effects of linc-UBC1 expression on the biological properties of CRC cells were examined using RNA interference experiments.

\section{Materials and methods Ethics statement}

The present study was authorized by the Research Ethics Review Board of Guangdong No 2 Provincial People's Hospital (Guangzhou, China), and each participant provided written informed consent.

\section{Tissue specimens}

Fresh clinical CRC specimens and adjacent normal tissues ( $\geq 5 \mathrm{~cm}$ from tumor tissues) were obtained from 96 patients who underwent surgical treatment for CRC between January 2010 and June 2011 at Guangdong No 2 Provincial People's Hospital. All specimens were harvested from patients who had not received chemotherapy or radiotherapy prior to surgery. All tissues were immediately placed in liquid nitrogen in a freezing tube following surgery and were stored at $-80^{\circ} \mathrm{C}$ until the extraction of total RNA was performed. All $\mathrm{CRC}$ and adjacent non-tumor mucosa tissues were confirmed by experienced pathologists. Clinicopathological information and follow-up data of the 96 patients were also collected.

\section{Cell culture conditions}

Four CRC cell lines (SW480, HCT116, HT29, and SW620) and an intestinal epithelial cell line (NCM460) were donated by Dr Jinjun Rao (College of Pharmacy, Southern Medical University, Guangzhou, China). The cancer cell lines were incubated in Gibco RPMI-1640 medium (Thermo Fisher Scientific, Waltham, MA, USA) while NCM460 cells were cultured in HyClone Dulbecco's Modified Eagle's Medium (GE Healthcare Life Sciences, Logan, UT, USA); both types of media were supplemented with $10 \%$ HyClone fetal bovine serum (FBS; GE Healthcare Life Sciences). Cells were cultured at $37^{\circ} \mathrm{C}$ in a humidified environment containing $5 \% \mathrm{CO}_{2}$.

\section{RNA extraction and reverse transcription (RT)-quantitative polymerase chain reaction ( $\mathrm{QPCR}$ ) analysis}

Total RNA was extracted from cultured cells or tissue specimens using RNAiso Plus (catalog no 9108Q; Takara Biotechnology Co., Ltd., Dalian, China) following the product manual. RNA was quantified using NanoDrop 2000 (Thermo Fisher Scientific) and stored at $-80^{\circ} \mathrm{C}$ until use. For each sample, total RNA (500 ng) from all cells and tissues was reverse transcribed to cDNA using the PrimeScript RT ${ }^{\mathrm{TM}}$ Master Mix (catalog no RR036A; Takara Biotechnology Co., Ltd.) following the manufacturer's protocol on a gradient PCR machine (Eppendorf China Ltd., Shanghai, China). Following the RT reaction, qPCR was employed to explore 
the relative expression patterns of linc-UBC1 with $\mathrm{SYBR}^{\circledR}$ Premix Ex Taq ${ }^{\text {TM }}$ II (catalog no RR820A; Takara Biotechnology Co., Ltd.) in an ABI 7500 System (Applied Biosystems; Thermo Fisher Scientific) according to the product manual. The primers used were as follows: linc-UBC1 forward, 5'-CGCTCTGCTCCAGTTATGTA-3'; linc-UBC1 reverse, 5'-GAAGGCAAGGAATGAGGTGG-3'; $\beta$-actin forward, 5'-CCTGGCACCCAGCACAAT-3'; and $\beta$-actin reverse, 5'-GGGCCGGACTCGTCATAC-3'. qPCR consisted of an initial denaturation step at $95^{\circ} \mathrm{C}$ for $30 \mathrm{~s}$, followed by 40 cycles of $95^{\circ} \mathrm{C}$ for $5 \mathrm{~s}$ and $60^{\circ} \mathrm{C}$ for $34 \mathrm{~s}$. The specificity of the PCR amplification was ascertained by the melting curve, which only had a single peak. The relative gene expression levels of linc-UBC1 were calculated using the comparative quantification cycle $(\mathrm{Cq})$ method $\left(2^{-\Delta \Delta \mathrm{Cq}}\right)$ using $\beta$-actin as the endogenous control.

\section{RNA interference}

The functional relevance of linc-UBC1 in CRC cell lines was investigated using linc-UBC1-specific small interfering RNAs (siRNAs). The nucleotide sequences of the siRNAs were as follows: si-linc-UBC1-1, 5'GGUUUCUGCCCUCAUCCUU-3'; si-linc-UBC1-2, 5'-GCUUCUAGUCCUCUCCUUA-3'; si-linc-UBC1-3, 5'-GCUGGAACCCAUUUACUAA-3'; and negative control (si-NC), 5'-CGUGGGUGGAUGCAUGGAUTT-3'. siRNAs were chemically synthesized by GenePharma Co. (Shanghai, China) and transfected into SW620 cells using Invitrogen Lipofectamine ${ }^{\mathrm{TM}} 2000$ transfection reagent (catalog no 11668-019; Thermo Fisher Scientific) according to the manufacturer's protocol. The silencing efficiency was evaluated at $48 \mathrm{~h}$ after transfection using RT-qPCR. The siRNA that demonstrated the most significant silencing capacity was further utilized for functional investigations in the cell line.

\section{Cell proliferation assay}

Cell viability was assessed using a cell counting kit- 8 (CCK-8) assay. Each well of a 96-well plate contained 5,000 transfected cells. Following incubation for $0,24,48,72$, or $96 \mathrm{~h}, 10 \mu \mathrm{L}$ CCK-8 solution was added to each well of the 96-well plate and incubated for $2 \mathrm{~h}$ in an incubator. The absorbance value was determined at $450 \mathrm{~nm}$ using a multimode microplate reader (Berthold Technologies $\mathrm{GmbH} \& \mathrm{Co}$. KG, Bad Wildbad, Germany).

\section{Flow cytometry analysis of cell cycle and apoptosis}

At $48 \mathrm{~h}$ after transfection, transfected SW620 cells were harvested by trypsinization and resuspended in cold phosphate-buffered saline for analysis. The rate of apoptosis in among the cells was detected by flow cytometry (BD Biosciences, Franklin Lakes, NJ, USA) using an Annexin V-fluorescein isothiocyanate and propidium iodide (PI) apoptosis detection kit (BD Biosciences) according to the manufacturer's protocol. Cells were distinguished into early apoptosis, late apoptosis, dead, and viable cell groups.

For the analysis of cell cycle, the resuspended cells were fixed and stained with PI using a Cycletest ${ }^{\mathrm{TM}}$ Plus DNA Reagent kit (BD Biosciences) according to the manufacturer's manual, and were detected by flow cytometry. The percentages of cells in $\mathrm{G} 0-\mathrm{G} 1, \mathrm{~S}$, and $\mathrm{G} 2-\mathrm{M}$ phases were ascertained using software (Flow Jo, 7.6.2; FLOWJO, LLC, Ashland, OR, USA).

\section{Western blot}

At $48 \mathrm{~h}$ after transfection, transfected SW620 cellular protein was extracted by a lysis buffer and quantified by a bicinchonininc acid kit (Beyotime, Shanghai, China). All the cellular protein lysates within this study were separated using $10 \%$ sodium dodecyl sulfate-polyacrylamide gel electrophoresis and transferred onto a polyvinylidene fluoride membrane. Then, the membrane was incubated with specific primary antihuman antibodies followed by their respective appropriate secondary antibodies. The bands were visualized by electrochemiluminescence automatic chemiluminescence imaging analysis system (Tanon, Shanghai, China). A GAPDH antibody was used as a control, and the anti-Bcl-2, cleaved caspase-3 and cleaved caspase-9 (all 1:1,000) antibodies were purchased from Cell Signaling Technology, Inc. USA.

\section{Cell migration and invasion assays}

SW620 cells transfected with si-linc-UBC1 or si-NC were harvested after $48 \mathrm{~h}$. The cells were resuspended in serum-free medium and diluted to $3 \times 10^{5}$ cells $/ \mathrm{mL}$, and $\sim 100 \mu \mathrm{L}$ of cell suspension was plated into the upper chambers of Transwell inserts $(8.0-\mu \mathrm{m}$ pore size; Costar; Corning Incorporated, Corning, NY, USA) for migration (without Matrigel) or invasion (with Matrigel) assays. The inserts were placed in 24-well plates containing $600 \mu \mathrm{L}$ media with $10 \%$ FBS as a chemoattractant. After incubation for $24 \mathrm{~h}$ for migration and $48 \mathrm{~h}$ for invasion, cells were fixed with $4 \%$ triformol for $20 \mathrm{~min}$ and stained with $1 \%$ crystal violet. From five random fields, cell numbers were calculated and imaged under a microscope.

\section{Statistical methods}

All statistical analyses were performed using SPSS version 20.0 (IBM SPSS, Armonk, NY, USA). Continuous variables were analyzed by the Student's $t$-test or one-way analysis 
of variance; normally distributed data were analyzed by Mann-Whitney $U$-test, and a Kruskal-Wallis test was used for data belonging to a non-normal distribution. Categorical variables were analyzed by the $\chi^{2}$ test. The overall survival rates were calculated by the Kaplan-Meier method, with the log-rank test applied for the comparison of differences. Hazard ratios were evaluated by univariate and multivariate Cox regression model. $P<0.05$ was considered to indicate a statistically significant difference.

\section{Results}

\section{Expression of linc-UBCI is upregulated in CRC cells and tissues}

The linc-UBC1 expression in 96 paired CRC tissues and matched non-tumor mucosa was assessed by RT-qPCR and the expression levels were normalized to $\beta$-actin. Significantly, the expression of linc-UBC1 was increased in CRC tissues compared with the paired adjacent normal tissues $(P<0.001$, Figure 1A). In addition, the expression of lincUBC1 in CRC cells was compared with intestinal epithelial cells, revealing that the expression levels of linc-UBC1 were upregulated in the majority of CRC cell lines (SW620, HCT116, and HT29) $(P<0.01$, Figure 2A). The SW620 cell line exhibited the highest expression level. However, no significant difference in expression was identified between SW480 and NCM460 cells.

\section{Overexpression of linc- $U B C I$ is associated with advanced TNM stages, large tumor size, greater tumor depth, lymph node metastasis, and poor prognosis of CRC}

To analyze the associations of linc-UBC1 expression with clinicopathological variables, patients were classified into a low linc-UBC1 expression group $(n=48)$ and a high linc-UBC1 expression group $(n=48)$, using the median expression level of linc-UBC1 in CRC tissues as a cutoff. Notably, high expression of linc-UBC1 was significantly associated with advanced TNM stages, large tumor size, greater tumor depth, and the presence of lymph node metastasis $(P<0.05$, Table 1$)$. However, no significant associations were identified between linc-UBC1 expression and other clinicopathological features, including patient gender, age, tumor location, differentiation status, and distant metastasis.

Kaplan-Meier survival analysis was used to determine the value of linc-UBC1 in the prognosis of CRC patients. Among the 96 CRC cases, the high linc-UBC1 expression group was obviously associated with shorter overall survival time $(P=0.002$, Figure 1B). Furthermore, multivariate analysis confirmed that high linc-UBC1 expression was a significant independent prognostic factor for overall survival in CRC patients ( $P=0.029$, Table 2 ). In addition, TNM stage and distant metastasis were also shown to be independent prognostic factors, after controlling for other clinicopathological factors $(P<0.05$, Table 2$)$.

\section{Manipulation of linc-UBCI levels in CRC cells}

The sizable increase in linc-UBC1 expression in CRC samples and cells prompted exploration of the possible biological significance of linc-UBC1 in tumorigenesis. Based on their relatively higher expression of linc-UBC1, SW620 cells were transfected with si-NC or si-linc-UBC1 designed to knockdown linc-UBC1. Following transfection for $48 \mathrm{~h}$, linc-UBC1 was effectively inhibited in SW620 cells $(P<0.001$, Figure 2B).

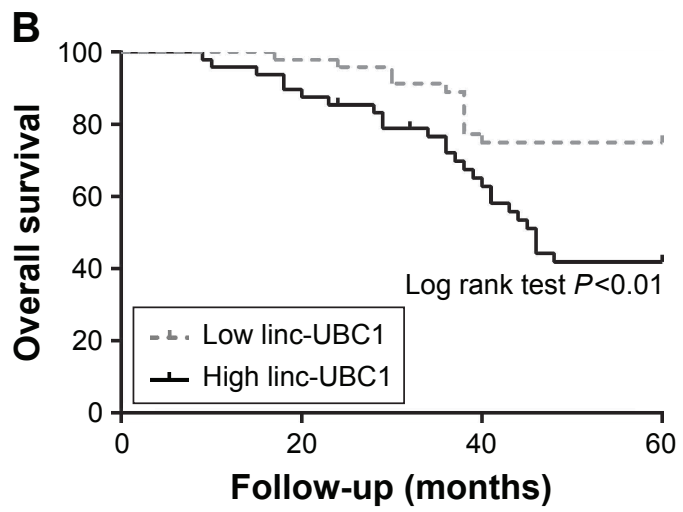

Figure I Expression of linc-UBCI and OS curves in 96 patients with CRC.

Notes: (A) The expression level of linc-UBCI in CRC tissues was significantly higher than that in its adjacent noncancerous epithelial tissues $(* P<0.00 \mathrm{I})$. (B) The OS time of the high linc- $\mathrm{UBCl}$ expression group of $\mathrm{CRC}$ patients was significantly shorter than that of the low expression group $(P=0.002)$.

Abbreviations: linc-UBCI, long non-coding RNA upregulated in bladder cancer I; OS, overall survival; CRC, colorectal carcinoma. 

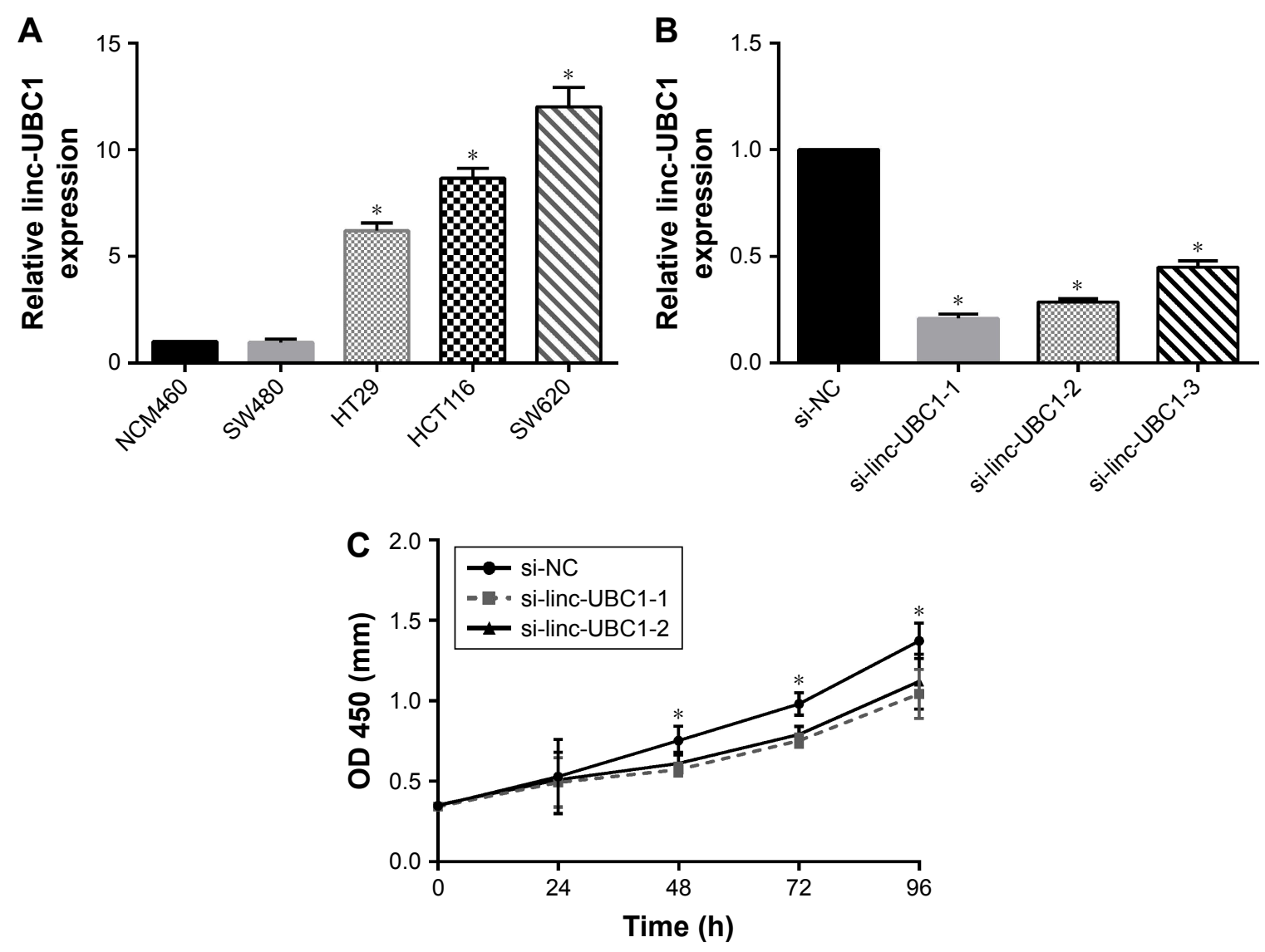

Figure 2 Expression of linc-UBCI in $\mathrm{CRC}$ and normal cells and its role in the regulation of proliferation.

Notes: (A) Expression of linc-UBCI was markedly higher in the majority of CRC cell lines (SW620, HCTII6, and HT29) compared with its expression in NCM460 colonic epithelial cells $(* P<0.01)$. The SW620 cell line exhibited the highest expression level. No difference in expression was identified between SW480 and NCM460 cells. (B) Following treatment with si-linc-UBCI, linc-UBCI expression in SW620 cell lines was significantly downregulated compared with that in si-NC-treated cells $(* P<0.00 \mathrm{I}$ ). (C) The siRNA-mediated silencing of linc-UBCI significantly inhibited cell proliferation in the SW620 cells $(* P<0.05)$.

Abbreviations: linc-UBCI, long non-coding RNA upregulated in bladder cancer I; CRC, colorectal carcinoma; siRNA, small interfering RNA; si-linc-UBCI, siRNA targeting linc-UBCI; si-NC, negative control siRNA; OD, optical density.

\section{linc-UBCI promotes proliferation of CRC cells}

After transfection, CCK-8 proliferation assays were conducted. The results revealed that proliferation of SW620 cells transfected with si-linc-UBC1-1 and si-linc-UBC1-2 was significantly inhibited compared with the si-NC-transfected SW620 cells $(P<0.05$, Figure 2C). Subsequently, flow cytometry was used to evaluate if the reduced proliferation of cells with low linc-UBC1 expression may be caused by cell cycle arrest or cell apoptosis. The results of the cell cycle analysis showed that the G2/M-phase fraction was increased from $8.14 \% \pm 0.27 \%$ in si-NC-transfected cells to $22.87 \% \pm 0.73 \%$ in si-linc-UBC1-1-transfected and $22.69 \% \pm 1.23 \%$ in si-linc-UBC1-2-transfected cells; this indicated $\mathrm{G} 2 / \mathrm{M}$ cell cycle arrest following linc-UBC1 knockdown $(P<0.01$, Figure 3B and C). Furthermore, the downregulation of linc-UBC1 induced a significant increase in the rate ( $14.23 \% \pm 0.89 \%$ in si-NC-transfected cells to $27.21 \% \pm 1.06 \%$ in si-linc-UBC1-1-transfected and $24.87 \% \pm 0.93 \%$ in silinc-UBC1-2-transfected cells) of apoptosis in SW620 cells $(P<0.001$, Figure $3 \mathrm{~A}$ and $\mathrm{D})$. Also, when transfected with si-linc-UBC1, cleaved caspase- 3 and cleaved caspase-9 were significantly increased, whereas Bcl-2 was decreased compared with si-NC-transfected SW620 cells $(P<0.05$, Figure 4). These findings indicate that linc-UBC1 inhibits $\mathrm{CRC}$ cell apoptosis at least partly through the activation of specific caspase cleavage cascades.

\section{linc-UBCI promotes migration and invasion of CRC cells}

Subsequently, to assess the effects of linc-UBC1 expression on CRC cell migration, a Transwell migration assay was performed using SW620 cells. As shown in the figures, fewer si-linc-UBC1-transfected SW620 cells migrated through the $8-\mu \mathrm{m}$ pores of the Transwell chambers when compared to the cells transfected with si-NC. Furthermore, similar results 
Table I Association between linc-UBCI expression and clinicopathological features in 96 patients with colorectal cancer

\begin{tabular}{|c|c|c|c|c|c|}
\hline \multirow[t]{2}{*}{ Factors } & \multirow[t]{2}{*}{$\begin{array}{l}\text { All cases, } \\
\text { n (\%) }\end{array}$} & \multicolumn{2}{|c|}{$\begin{array}{l}\text { linc-UBCI } \\
\text { expression }\end{array}$} & \multirow[t]{2}{*}{$x^{2}$} & \multirow[t]{2}{*}{$P$-value } \\
\hline & & $\begin{array}{l}\text { Low, } \\
\text { n (\%) }\end{array}$ & $\begin{array}{l}\text { High, } \\
\text { n (\%) }\end{array}$ & & \\
\hline \multicolumn{6}{|c|}{ Age at diagnosis (years) } \\
\hline$<60$ & $49(51.0)$ & $25(51.0)$ & $24(49.0)$ & 0.042 & 0.838 \\
\hline$\geq 60$ & $47(49.0)$ & $23(48.9)$ & $24(5 I . I)$ & & \\
\hline \multicolumn{6}{|l|}{ Gender } \\
\hline Male & $62(64.6)$ & $29(46.8)$ & $33(53.2)$ & 0.729 & 0.393 \\
\hline Female & $34(35.4)$ & $19(55.9)$ & I5 (44.I) & & \\
\hline \multicolumn{6}{|l|}{ Tumor location } \\
\hline Colon & $49(51.0)$ & $23(46.9)$ & $26(53.1)$ & 0.375 & 0.540 \\
\hline Rectum & $47(49.0)$ & $25(53.2)$ & $22(46.8)$ & & \\
\hline \multicolumn{6}{|l|}{ Tumor size } \\
\hline$<5.0 \mathrm{~cm}$ & $50(52.1)$ & $34(68.0)$ & $16(32.0)$ & 13.523 & 0.001 \\
\hline$\geq 5.0 \mathrm{~cm}$ & 46 (47.9) & $14(30.4)$ & $32(69.6)$ & & \\
\hline \multicolumn{6}{|l|}{ Differentiation status } \\
\hline Poor & $35(36.5)$ & $14(40.0)$ & $21(60.0)$ & 2.203 & 0.138 \\
\hline Moderate or high & $6 \mathrm{I}(63.5)$ & $34(55.7)$ & $27(44.3)$ & & \\
\hline \multicolumn{6}{|l|}{ Depth of invasion } \\
\hline $\mathrm{TI}+\mathrm{T} 2$ & $18(18.8)$ & I3 (72.2) & $5(27.8)$ & 4.376 & 0.036 \\
\hline $\mathrm{T} 3+\mathrm{T} 4$ & $78(81.2)$ & $35(44.9)$ & $43(55.1)$ & & \\
\hline \multicolumn{6}{|c|}{ Lymph node metastasis } \\
\hline No & $58(60.4)$ & $35(60.3)$ & $23(39.7)$ & 6.672 & 0.012 \\
\hline $\mathrm{NI}+\mathrm{N} 2$ & $38(39.6)$ & $13(34.2)$ & $25(65.8)$ & & \\
\hline \multicolumn{6}{|l|}{ Distant metastasis } \\
\hline Mo & $85(88.5)$ & $43(50.6)$ & $42(49.4)$ & 0.103 & 0.749 \\
\hline MI & II (II.5) & $5(45.5)$ & $6(54.5)$ & & \\
\hline \multicolumn{6}{|l|}{ TNM stage } \\
\hline$I+I I$ & $55(57.3)$ & $33(60.0)$ & $22(40.0)$ & 5.151 & 0.023 \\
\hline III + IV & $4 \mid(42.7)$ & $15(36.6)$ & $26(63.4)$ & & \\
\hline
\end{tabular}

Abbreviation: linc-UBCI, long non-coding RNA upregulated in bladder cancer I.

Table 2 Multivariate analysis by Cox regression model of factors associated with OS in 96 patients with colorectal cancer

\begin{tabular}{|c|c|c|c|}
\hline \multirow[t]{2}{*}{ Factors } & \multicolumn{3}{|l|}{ OS } \\
\hline & $\begin{array}{l}\text { Hazard } \\
\text { ratio }\end{array}$ & $95 \% \mathrm{Cl}$ & $P$-value \\
\hline Age at diagnosis (years) $(<60$ vs $\geq 60$ ) & 1.093 & $0.545-2.189$ & 0.803 \\
\hline Gender (male vs female) & 1.227 & $0.58 I-2.59 I$ & 0.591 \\
\hline Tumor location (colon vs rectum) & 1.446 & $0.709-2.946$ & 0.310 \\
\hline Tumor size $(<5.0 \mathrm{vs} \geq 5.0 \mathrm{~cm})$ & $1.87 \mid$ & $0.914-3.831$ & 0.086 \\
\hline Differentiation status (GI + G2 vs G3) & 0.720 & $0.315-1.646$ & 0.436 \\
\hline $\begin{array}{l}\text { Depth of invasion (TI + T2 vs } \\
\mathrm{T} 3+\mathrm{T} 4)\end{array}$ & 1.463 & $0.320-6.696$ & 0.624 \\
\hline $\begin{array}{l}\text { Lymph node metastasis (N0 vs } \\
\mathrm{NI}+\mathrm{N} 2 \text { ) }\end{array}$ & 0.539 & $0.158-1.837$ & 0.323 \\
\hline Distant metastasis (M0 vs MI) & 4.016 & $1.476-10.926$ & 0.006 \\
\hline TNM stage (I + II vs III + IV) & 4.977 & $1.264-19.605$ & 0.022 \\
\hline linc-UBCI expression (high vs low) & 2.434 & $1.093-5.420$ & 0.029 \\
\hline
\end{tabular}

Abbreviations: OS, overall survival; linc-UBCI, long non-coding RNA upregulated in bladder cancer I; $\mathrm{Cl}$, confidence interval. were obtained in the invasion assay in which Transwell chambers were pre-coated with Matrigel ( $P<0.01$, Figure 5). According to the results of this study, it is concluded that the migration and invasion capabilities of CRC cells were significantly inhibited following the knockdown of linc-UBC1.

\section{Discussion}

Previous studies have demonstrated that abnormal lncRNA expression may be a crucial contributor to tumorigenesis. ${ }^{13-19}$ The biological processes that may be affected by lncRNA expression include chromosome imprinting, cytoplasmic transport, X-chromosome inactivation, and cell differentiation. ${ }^{24,25}$ These findings indicate that lncRNAs may act as independent biomarkers for prognosis and diagnosis. linc-UBC1, which physically associates with PRC2, may play an important role in the occurrence and development of tumors, and has been found to be upregulated in bladder and gastric cancers. ${ }^{20,21}$ However, the exact function of lincUBC1 in CRC remains unknown.

The results of the present study revealed that linc-UBC1 was significantly overexpressed in CRC tissues compared with that in corresponding noncancerous tissue. Furthermore, the expression of linc-UBC1 in the majority of the CRC cell lines was higher than that in NCM460 normal intestinal epithelial cells. Statistical analysis revealed that high linc-UBC1 expression level was associated with various clinicopathological features of CRC, including large tumor size, greater tumor depth, lymph node metastasis, and advanced TNM stages. To evaluate the contribution of linc-UBC1 to the regulation of CRC, its expression was knocked down in the SW620 cell line, and the subsequent proliferation results showed that reduced expression of linc-UBC1 inhibited cell growth. Furthermore, flow cytometry analyses indicated that decreased expression of linc-UBC1 induced cell apoptosis and cell cycle arrest. Therefore, it is considered that the suppression of cell proliferation may be due to the induction of cell cycle arrest and promotion of apoptosis. Furthermore, the protein levels of Bcl-2, cleaved caspase-3, cleaved caspase-9 indicate that lincUBC1 inhibits CRC cell apoptosis through the activation of specific caspase cleavage cascades. The decrease in linc-UBC1 expression was also shown to suppress CRC cell migration and invasion ability in vitro. These findings suggest that linc-UBC1 promotes cell proliferation and metastasis in CRC.

With regard to the molecular mechanism of linc-UBC1, it has been confirmed that linc-UBC1 directly interacts with PRC2 and that overexpression promotes cancer progression and poor prognosis of bladder cancer patients. ${ }^{20}$ The PRC2 

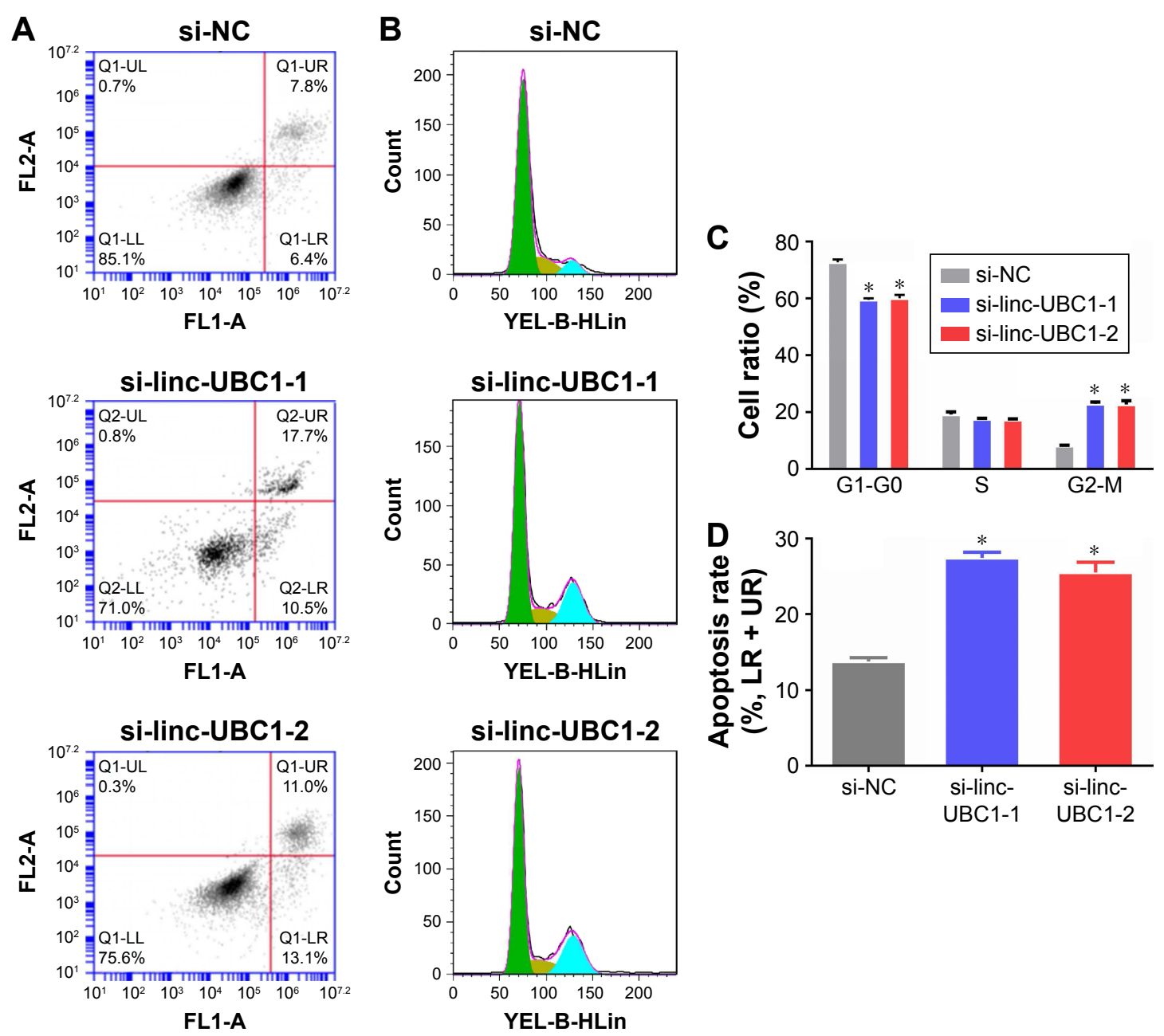

Figure 3 Impact of linc-UBCI on apoptosis and cell cycle distribution of SW620 cells as analyzed by flow cytometry.

Notes: (A) Image of cell apoptosis. (B) Image of cell cycle. (C) Downregulation of linc-UBCI induced cell cycle arrest at the G2/M phase (*P<0.0I). (D) In comparison with si-NC-transfected cells, induction of cell apoptosis was observed in si-linc-UBCI-transfected cells $(* P<0.00 \mathrm{I})$.

Abbreviations: linc-UBCI, long non-coding RNA upregulated in bladder cancer I; si-NC, negative control siRNA; si-linc-UBCI, siRNA targeting linc-UBCI; siRNA, small interfering RNA; LR, lower right quadrant; UR, upper right quadrant.

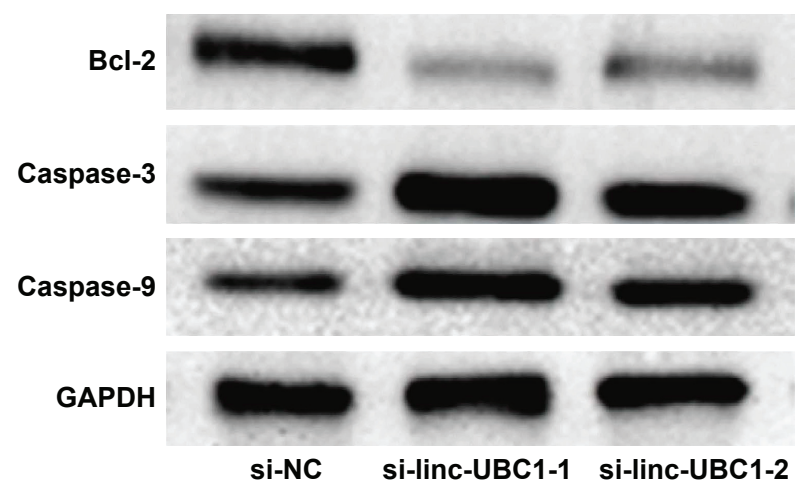

Figure 4 Results of the Western blot analysis of the levels of $\mathrm{Bcl}-2$, cleaved caspase-3, cleaved caspase-9, and GAPDH.

Notes: When transfected with si-linc-UBCI, cleaved caspase- 3 and cleaved caspase-9 were significantly increased, whereas $\mathrm{Bcl}-2$ was decreased compared with si-NC-transfected cells $(P<0.05)$.

Abbreviations: si-NC, negative control siRNA; si-linc-UBCl, siRNA targeting linc-UBCI; siRNA, small interfering RNA; GAPDH, glyceraldehyde-3-phosphate dehydrogenase. complex has an important role in carcinogenesis by repressing transcription via histone $\mathrm{H} 3$ lysine 27 (H3K27), ${ }^{26}$ and a substantial proportion (24\%) of IncRNAs is associated with this complex. ${ }^{22,23}$ For example, the lncRNA HOTAIR physically associates with PRC2, which is composed of SUZ12 and $\mathrm{EZH} 2$, to promote the progression of various cancer types, including gastrointestinal cancer, ${ }^{27}$ breast cancer, ${ }^{13}$ and hepatocellular carcinoma. ${ }^{28}$ Furthermore, compared with the functional mechanism of linc-UBC1 in bladder cancer, ${ }^{20}$ a similar mechanism may exist in CRC; however, further research is still required to demonstrate the precise molecular mechanisms of linc-UBC1 in CRC.

In the present study, Kaplan-Meier analysis indicated that patients with high levels of linc-UBC1 expression had markedly shorter overall survival time compared to patients 
A

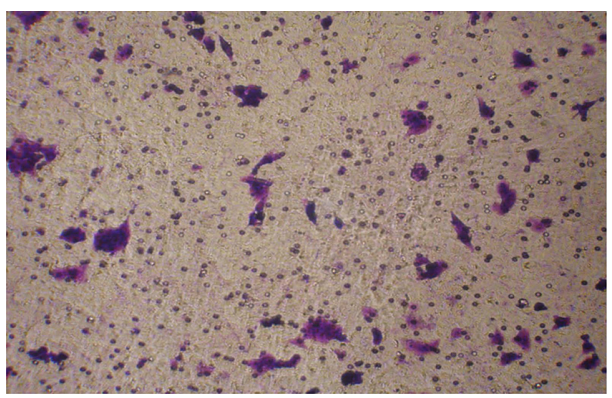

si-NC

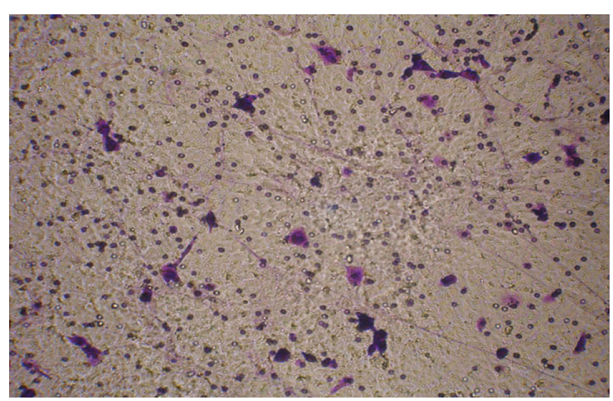

si-linc-UBC1-2

B

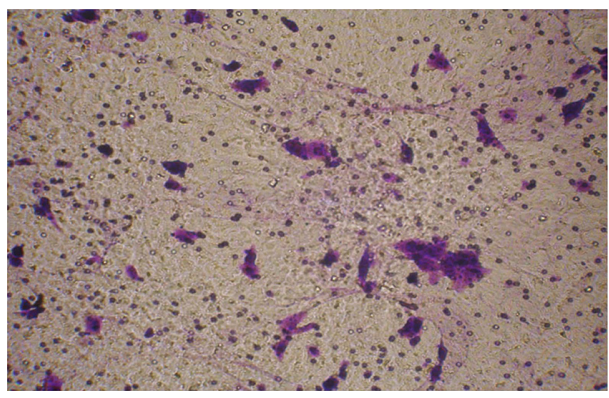

si-NC

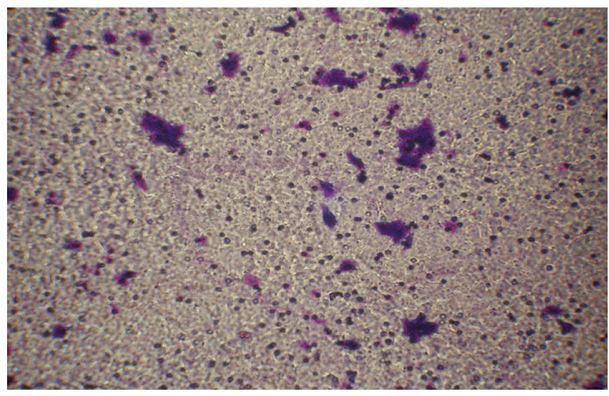

si-linc-UBC1-2

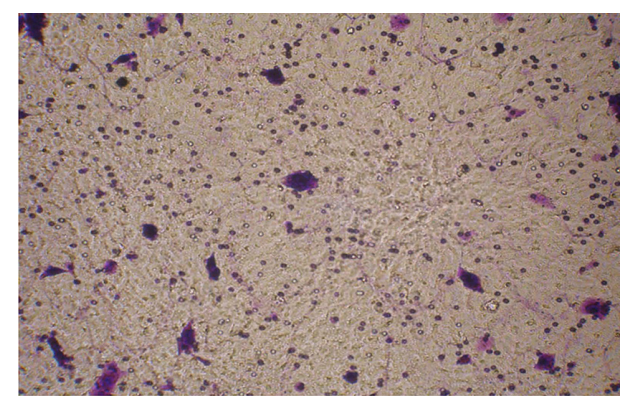

si-linc-UBC1-1
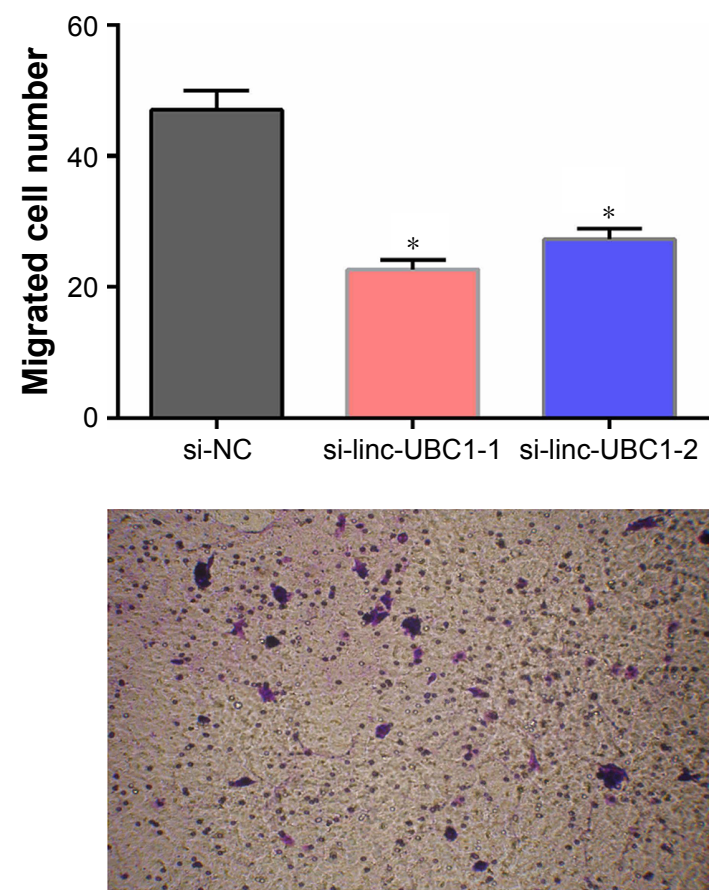

si-linc-UBC1-1

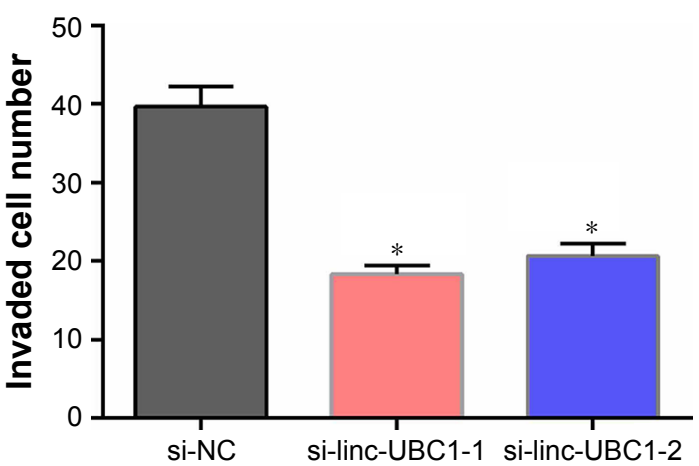

Figure 5 Impact of linc-UBCI on the migration and invasion of SW620 cells (crystal violet staining; original magnification, $\times 200$ ).

Notes: $(\mathbf{A})$ When transfected with si-linc-UBCI, fewer SW620 cells migrated through the basement membrane compared with si-NC-transfected cells $(* P<0.01)$. (B) When transfected with si-linc-UBCI, fewer SW620 cells invaded through the basement membrane compared with si-NC-transfected cells $(* P<0.01)$.

Abbreviations: linc-UBCI, long non-coding RNA upregulated in bladder cancer I; si-linc-UBCI, siRNA targeting linc-UBCI; si-NC, negative control siRNA; siRNA, small interfering RNA.

with low expression. Multivariate analysis further revealed that linc-UBC1 expression was a significant independent prognostic factor for poor survival of CRC patients. These results indicate that upregulation of linc-UBC1 may have a prominent role in CRC development and progression.
In summary, the present study is the first to report that linc-UBC1 is upregulated in CRC tumor tissues and is associated with tumor size, tumor depth, lymph node metastasis, and TNM stage. Furthermore, the results suggested that linc$\mathrm{UBC} 1$ is an independent predictor of poor overall survival 
of patients with CRC. Knockdown of linc-UBC1 significantly inhibited proliferation and invasion in vitro. Understanding the critical role of linc-UBC1 in CRC may lead to the development of a novel diagnostic marker for this type of cancer. However, the molecular mechanisms by which linc-UBC1 regulates the $\mathrm{CRC}$ cancer migration and invasion require further investigation. As this study is the first to report the biological functions of linc-UBC1 in CRC cancer, further studies in a larger number of samples and investigations of the other possible mechanisms of action are required.

\section{Acknowledgments}

The authors thank Spandidos Publications for helping with critical reading of the manuscript. Thanks are due to Dr Jinjun Rao (College of Pharmacy, Southern Medical University) for gifting the CRC cells and intestinal epithelial cells. This study was financially supported by the science foundation of Guangdong No 2 Provincial People's Hospital (YQ2015-007).

\section{Disclosure}

The authors report no conflicts of interest in this work.

\section{References}

1. Siegel RL, Miller KD, Jemal A. Cancer statistics, 2015. CA Cancer J Clin. 2015;65(1):5-29.

2. Chen W, Zheng R, Zhang S, Zhao P, Zeng H, Zou X. Report of cancer incidence and mortality in China, 2010. Ann Transl Med. 2014; 2(7):1-25.

3. Rupnarain C, Dlamini Z, Naicker S, Bhoola K. Colon cancer: genomics and apoptotic events. Biol Chem. 2004;385(6):449-464.

4. Calvert PM, Frucht H. The genetics of colorectal cancer. Ann Intern Med. 2002;137(7):603-612.

5. Edwards BK, Ward E, Kohler BA, et al. Annual report to the nation on the status of cancer, 1975-2006, featuring colorectal cancer trends and impact of interventions (risk factors, screening, and treatment) to reduce future rates. Cancer. 2010;116(3):544-573.

6. Colussi D, Brandi G, Bazzoli F, Ricciardiello L. Molecular pathways involved in colorectal cancer: implications for disease behavior and prevention. Int J Mol Sci. 2013;14(8):16365-16385.

7. Vaiopoulos AG, Athanasoula KC, Papavassiliou AG. Epigenetic modifications in colorectal cancer: molecular insights and therapeutic challenges. Biochim Biophys Acta. 2014;1842(7):971-980.

8. Brockdorff N, Ashworth A, Kay GF, et al. The product of the mouse Xist gene is a $15 \mathrm{~kb}$ inactive $\mathrm{X}$-specific transcript containing no conserved ORF and located in the nucleus. Cell. 1992;71(3):515-526.

9. Lee JT, Bartolomei MS. X-inactivation, imprinting, and long noncoding RNAs in health and disease. Cell. 2013;152(6):1308-1323.

10. Yoon J-H, Abdelmohsen K, Gorospe M. Posttranscriptional gene regulation by long noncoding RNA. J Mol Biol. 2013;425(19):3723-3730.
11. Marchese FP, Huarte M. Long non-coding RNAs and chromatin modifiers: their place in the epigenetic code. Epigenetics. 2014;9(1):21-26.

12. Ulitsky I, Bartel DP. lincRNAs: genomics, evolution, and mechanisms. Cell. 2013;154(1):26-46.

13. Gupta RA, Shah N, Wang KC, et al. Long non-coding RNA HOTAIR reprograms chromatin state to promote cancer metastasis. Nature. 2010;464(7291):1071-1076.

14. Huang JF, Guo YJ, Zhao CX, et al. Hepatitis B virus X protein (HBx)-related long noncoding RNA (lncRNA) down-regulated expression by $\mathrm{HBx}$ (Dreh) inhibits hepatocellular carcinoma metastasis by targeting the intermediate filament protein vimentin. Hepatology. 2013;57(5):1882-1892.

15. Saito T, Kurashige J, Nambara S, et al. A long non-coding RNA activated by transforming growth factor- $\beta$ is an independent prognostic marker of gastric cancer. Ann Surg Oncol. 2015;22(3):915-922.

16. Chen Z, Li J-L, Lin S, et al. cAMP/CREB-regulated LINC00473 marks LKB1-inactivated lung cancer and mediates tumor growth. J Clin Invest. 2016;126(6):2267-2279.

17. Ylipää A, Kivinummi K, Kohvakka A, et al. Transcriptome sequencing reveals PCAT5 as a novel ERG-regulated long noncoding RNA in prostate cancer. Cancer Res. 2015;75(19):4026-4031.

18. Xiang JF, Yin QF, Chen T, et al. Human colorectal cancer-specific CCAT1-L lncRNA regulates long-range chromatin interactions at the MYC locus. Cell Res. 2014;24(5):513-531.

19. Kim T, Jeon YJ, Cui R, et al. Role of MYC-regulated long noncoding RNAs in cell cycle regulation and tumorigenesis. J Natl Cancer Inst. 2015;107(4):505-515.

20. He W, Cai Q, Sun F, et al. linc-UBC1 physically associates with polycomb repressive complex 2 (PRC2) and acts as a negative prognostic factor for lymph node metastasis and survival in bladder cancer. Biochim Biophys Acta. 2013;1832(10):1528-1537.

21. Hu Y, Pan J, Wang Y, Li L, Huang Y. Long noncoding RNA linc-UBC1 is negative prognostic factor and exhibits tumor pro-oncogenic activity in gastric cancer. Int J Clin Exp Pathol. 2015;8(1):594-600.

22. Khalil AM, Guttman M, Huarte M, et al. Many human large intergenic noncoding RNAs associate with chromatin-modifying complexes and affect gene expression. Proc Natl Acad Sci U S A. 2009;106(28): 11667-11672.

23. Yao Y, Li J, Wang L. Large intervening non-coding RNA HOTAIR is an indicator of poor prognosis and a therapeutic target in human cancers. Int J Mol Sci. 2014;15(10):18985-18999.

24. Wilusz JE, Sunwoo H, Spector DL. Long noncoding RNAs: functional surprises from the RNA world. Genes Dev. 2009;23(13):1494-1504.

25. Guttman M, Donaghey J, Carey BW, et al. lincRNAs act in the circuitry controlling pluripotency and differentiation. Nature. 2011; 477(7364):295-300.

26. Holm K, Grabau D, Lövgren K, et al. Global H3K27 trimethylation and EZH2 abundance in breast tumor subtypes. Mol Oncol. 2012; 6(5):494-506.

27. Niinuma T, Suzuki H, Nojima M, et al. Upregulation of miR-196a and HOTAIR drive malignant character in gastrointestinal stromal tumors. Cancer Res. 2012;72(5):1126-1136.

28. Geng Y, Xie S, Li Q, Ma J, Wang G. Large intervening non-coding RNA HOTAIR is associated with hepatocellular carcinoma progression. J Int Med Res. 2011;39(6):2119-2128. 


\section{Publish your work in this journal}

OncoTargets and Therapy is an international, peer-reviewed, open access journal focusing on the pathological basis of all cancers, potential targets for therapy and treatment protocols employed to improve the management of cancer patients. The journal also focuses on the impact of management programs and new therapeutic agents and protocols on

patient perspectives such as quality of life, adherence and satisfaction. The manuscript management system is completely online and includes a very quick and fair peer-review system, which is all easy to use. Visit http://www.dovepress.com/testimonials.php to read real quotes from published authors.

Submit your manuscript here: http://www.dovepress.com/oncotargets-and-therapy-journal 